\title{
The Influence of Drug Loading on Caveolin-1 Mediated Intracellular Internalization of Doxorubicin Nanomicelles in vitro
}

Hayley Nehoff', Neha N. Parayath ${ }^{1}$, Sebastien Taurin ${ }^{1 *}$ and Khaled Greish ${ }^{1,2 *}$

${ }^{1}$ Department of Pharmacology and Toxicology, University of Otago, Dunedin, New Zealand

${ }^{2}$ Department of Oncology, Faculty of Medicine, Suez Canal University, Egypt

\begin{abstract}
Despite the considerable progress made in the field of anticancer nanomedicine, the influence of the physicochemical characteristics of the nanoconstructs on their internalization and cytotoxicity towards specific cancer cells remains to be fully understood. The aim of this in vitro study was to examine the factors influencing the potency of styrene maleic acid (SMA-Dox) micelles loaded with doxorubicin in a range of $4.4 \%$ to $28.4 \%$ using breast cancer and prostate cancer cell lines. A significant difference in cytotoxicity relative to micelle loading was observed and correlated with the expression level of caveolin-1. The expression level of caveolin-1 has previously been associated with advanced, aggressive cancer subtypes. For example, SMA-Dox micelles were shown to co-localize with caveolin-1 in PC3 cells and this colocalization was disrupted by treatment with the caveolin-1 inhibitor, genistein. The results of this study are indicative that the micelle loading and cellular expression of caveolin-1 modulates the relative cytotoxicity of nanoconstructs of different loading against breast and prostate cancer cell lines in vitro. The expression level of caveolin-1 is a factor to consider when developing nanoconstructs for the treatment of breast and prostate cancers.
\end{abstract}

Keywords: Micelle; SMA; Enhanced permeability and retention effect; Endocytosis; Caveolin; Breast cancer; Prostate cancer

\section{Background}

The use of nanomedicine for the treatment of cancer has been a promising field for the past 25 years but, despite promising efficacy in animal studies, only nine nanomedicines have successfully transition to the clinics and approved for the treatment of various cancers [1]. A potential explanation for this disappointing clinical translation is the lack of understanding of the relationship between the physicochemical characteristics of the nanomedicine and the characteristics of the tumour.

Doxorubicin is a member of the anthracycline group and is one of

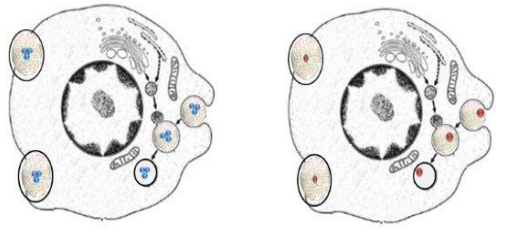

High Caveolin

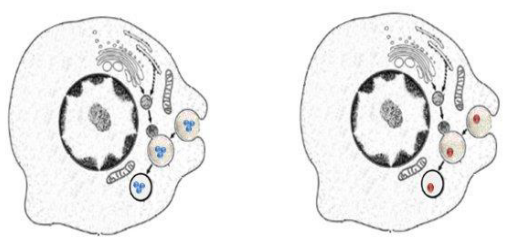

Low Caveolin
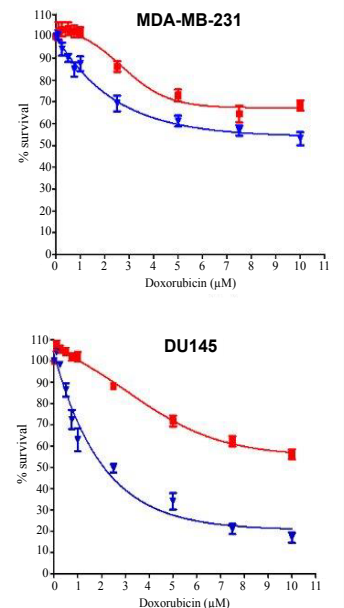

Figure 1: Schematic representation of the effect of loading on internalization and the cytotoxicity of SMA-Dox micelles with high loading (blue) and low loading (red) against MDA-MB 231 overexpressing caveolin-1 and DU145 cells that under-express caveolin-1. In cells will low caveolin-1 expression, the cytotoxicity is heavily dependent on micelle loading Conversely, in cells with high expression of caveolin-1, Such as MDA-MB-231 cells, the cytotoxicity is similar across the different loadings as micelle uptake is nonrate limiting. the most potent and widely used anticancer agents. Doxorubicin has been approved for the treatment of a broad range of cancers including breast, prostate, lymphoma, sarcoma and leukaemia [2]. The proposed mechanisms by which doxorubicin induces cell death in cancer cells includes the rapid intercalation of doxorubicin to DNA, perturbation of topoisiomerase II activity, formation of DNA adducts and inhibition of DNA methyl transferase [3]. Furthermore, the generation of free radicals induces damage to cell membranes through lipid peroxidation, oxidative stress and DNA and protein damage which promote apoptosis mediated cell death [4]. Unfortunately, the cytotoxicity of doxorubicin as the majority of anticancer agents lacks specificity to cancer cells and leads to severe side-effects. This nonselective cytotoxicity is the main limitation to the use of higher doses. Doxorubicin is indiscriminately distributed via simple diffusion to different organs and tissues [5], and produces dose-limiting cardiac toxicity due to oxidative stress damaging the cardiac muscle [6]. In contrast, encapsulation of doxorubicin into nanomedicine increases its molecular weight and modified its pharmacokinetic profile. Approved nanomedicines formulations such as Doxil and Myocet show reduced cardiotoxicity relative to free doxorubicin $[7,8]$. (Figure 1)

Encapsulation of doxorubicin into a nanomedicine carrier also allows the drug to accumulate preferentially in tumor tissue, a

*Corresponding authors: Khaled Greish, Department of Pharmacology and Toxicology, University of Otago, Adams Building, $3^{\text {rd }}$ floor, 18, Frederick Street, Dunedin, New Zealand, Tel: +64 3479 4095; Fax: +64 3479 9140; E-mail: khaled.greish@otago.ac.nz

Sebastien Taurin, Department of Pharmacology and Toxicology, University of Otago, Adams Building, $3^{\text {rd }}$ floor, 18, Frederick Street, Dunedin, New Zealand, Tel: +64 3479 4095; Fax: +64 3479 9140; E-mail: sebastien.taurin@otago.ac.nz

Received March 28, 2014; Accepted April 24, 2014; Published April 28, 2014

Citation: Nehoff H, Parayath NN, Taurin S, Greish K (2014) The Influence of Drug Loading on Caveolin-1 Mediated Intracellular Internalization of Doxorubicin Nanomicelles in vitro. J Nanomed Nanotechnol 5: 197. doi:10.4172/21577439.1000197

Copyright: (C) 2014 Nehoff $\mathrm{H}$, et al. This is an open-access article distributed under the terms of the Creative Commons Attribution License, which permits unrestricted use, distribution, and reproduction in any medium, provided the original author and source are credited. 
phenomenon known as the enhanced permeability and retention (EPR) effect [9]. As tumors develop, the cancer cells stimulate angiogenesis and promote vascular permeability. The emerging blood vessels show abnormal morphology including wide endothelial gaps, lack of pericytes, and smooth muscle layer, resulting in a high vascular permeability of dilated, tortuous tumor vessels $[10,11]$. These abnormalities allow the extravasation of large molecular weight constructs into the tumour tissue while the absence of functional lymphatics allows the constructs the be retained in the tissue [12]. However, the clinical efficacy of nanomedicines has been lower than expected, a paradox which suggests alternate variables need to be considered with respect to nanomedicine application.

Our laboratory has formulated doxorubicin micelles using styrene maleic acid (SMA) as a carrier. The micelles had a weight/weight loading of $4.4,14.5$, and $28.4 \%$ doxorubicin and were assessed based on their relative toxicity towards breast and prostate cancer cell lines. This cytotoxicity was compared to cellular parameters such as the level of caveolin-1 expression.

\section{Methods}

\section{Materials and Methods}

SMA, (MW 1,600), foetal bovine serum, N-(3dimethylaminopropyl)-N-ethylcarbodiimide hydrochloride (EDAC) was purchased from Sigma-Aldrich Ltd. (Auckland, New Zealand). Antibodies were purchased from Cell Signalling Technology (Boston, USA). Antibodies used were: Caveolin-1 (D46G3) XP' Rabbit mAb \#3267, Clathrin Heavy Chain (D3C6) XP ${ }^{\circ}$ Rabbit mAb \#4796, early endosome antigen 1 (EEA1) (C45B10) Rabbit mAb \#3288 and $\beta$-Tubulin Antibody \#2146.

\section{Cell culture}

PC3, MDA-MB-231, DU145 and MCF-7 cells were obtained from the American type culture collection (ATCC), Manassas USA and all experiments were conducted with cells below passage 30 . Cell lines were maintained in complete growth media DMEM/Ham's F12 supplemented with $5 \%$ fetal bovine serum, $2 \mathrm{mM} \mathrm{L-Glutamine,}$ 100 units $/ \mathrm{ml}$ penicillin, $100 \mathrm{units} / \mathrm{ml}$ of streptomycin and $2.2 \mathrm{~g} / \mathrm{l}$ of $\mathrm{NaHCO}_{3}$. For all procedures, cells were harvested using TrypLE Express (Life Technologies, Auckland, New Zealand) and were maintained at $37^{\circ} \mathrm{C}$ in humidified atmosphere of $5 \% \mathrm{CO}_{2}$.

\section{Synthesis}

Micelles were synthesized as described previously [13]. Briefly anhydrous SMA $(10 \mathrm{mg} / \mathrm{ml})$ was adjusted to $\mathrm{pH} 5.0$ and $\mathrm{N}-(3-$ Dimethylaminopropyl)-N'-ethylcarbodiimide (EDAC) and doxorubicin was added to the solution. The $\mathrm{pH}$ was maintained at 5.0 until stabilisation which indicated that all Maleic acid groups had reacted with the EDAC in order to allow interaction of the styrene moieties with the drug. Following stabilization, the $\mathrm{pH}$ was then raised to 11.0 to remove the EDAC and allow the micelle to form. The solution was then adjusted to $\mathrm{pH} 7.4$ and the solution was filtered 4 times through a $10,000 \mathrm{Da}$ cutoff membrane to filter out excess doxorubicin, EDAC and salts. This solution was lyophilised. $4.44 \%$ micelles were synthesised with a target loading of $10 \%$ and utilized $180 \mathrm{mg}$ of SMA, $180 \mathrm{mg}$ of EDAC, and $20 \mathrm{mg}$ of doxorubicin. $14.5 \%$ micelles were synthesised with a target loading of $20 \%$ and utilized $160 \mathrm{mg}$ of SMA, $160 \mathrm{mg}$ of EDAC and $40 \mathrm{mg}$ of doxorubicin. $28.4 \%$ micelles were synthesised with a target loading of $40 \%$ and utilized $120 \mathrm{mg}$ of SMA, $120 \mathrm{mg}$ of EDAC and $80 \mathrm{mg}$ of doxorubicin. Loading was determined by disrupting the micelles in $90 \%$ DMSO and measured compared to a standard curve of doxorubicin measured at $479 \mathrm{~nm}$.

\section{Characterisation}

Size and charge: SMA-Dox micelles $(5 \mathrm{mg} / \mathrm{ml})$ were solubilized in water. All measurements for size distribution and zeta potential were performed using the Malvern ZEN3600 Zetasizer nano series (Malvern Instruments Inc., Westborough, MA). All measurements were conducted in triplicate and from three independent experiments.

Drug release: Micelles were dissolved in PBS ( $\mathrm{pH}$ 7.4) at a concentration of $1 \mathrm{mg} / \mathrm{ml}$ and placed in a $12,000 \mathrm{kDa}$ cutoff dialysis membrane. The micelles were dialysed against $\mathrm{pH} 7.4 \mathrm{PBS}$ at $37^{\circ} \mathrm{C}, 75$ RPM for 96 hours. At the indicated times, $2 \mathrm{ml}$ of the solution outside the bag was removed and the absorbance read at $479 \mathrm{~nm}$ before the PBS was replaced into the tube. Quantification of the percentage of release was determined by the ratio of the absorbance of the outside bag at defined time point over the absorbance inside the bag at $t=0$. All experiments were performed in triplicate. Percentage release is reported as mean \pm standard error.

\section{In vitro Cytotoxicity}

MDA-MB-231 and MCF7 human breast cancer cell lines, and DU145 and PC3 human prostate cell lines, were seeded into 96-well plates and incubated for 24 hours. Doxorubicin was applied at the concentrations indicated and the cells were incubated for 72 hours. Following the incubation the cells were fixed using trichloro-acetic acid (TCA). Cell number was determined using the sulforhodamine B assay [14].

The concentration required to decrease the cell number by $50 \%$ $\left(\mathrm{IC}_{50}\right)$ was determined by non-linear regression using Prism software. Experiments were performed in triplicate and from three independent experiments.

\section{Intracellular internalisation of micellar formulations}

MDA-MB-231, MCF7, PC3, and DU145 cells $\left(8 \times 10^{4}\right.$ cells per well) were seeded in 6-well plates and treated with $100 \mu \mathrm{M}$ doxorubicin equivalent when the cells reached approximately $80 \%$ confluency. After 6 hours, the cells were trypsinized and prepared for fluorescenceactivated cell sorting (FACS) [15]. Briefly, media was removed; cells were trypsinized, washed two times with $\mathrm{PBS}$ and re-suspended in FACS binding buffer (Hepes $10 \mathrm{mM}$ pH 7.4, $\mathrm{NaCl} 140 \mathrm{mM}, \mathrm{CaCl}_{2} 5$ $\mathrm{mM})$. Internalization was measured by the inherent fluorescence of doxorubicin.

\section{Western Blot}

PC3, MDA-MB-231, MCF7 and DU145 cells $\left(4 \times 10^{4}\right.$ cells per well) were seeded in 12-well plates in $1 \mathrm{ml}$ of complete growth media and incubated for 36 hours. Cells were lyzed in buffer containing 50 $\mathrm{mM}$ Tris- $\mathrm{HCl}(\mathrm{pH} 8), 150 \mathrm{mM} \mathrm{NaCl}$, and $1 \%$ Triton X-100, $1 \%$ SDS, $1 \mathrm{mM}$ sodium fluoride, $200 \mu \mathrm{M}$ sodium orthovanadate, and protease inhibitors $(1 \mu \mathrm{g} / \mathrm{ml}$ leupeptin, $1 \mu \mathrm{g} / \mathrm{ml}$ aprotinin, $1 \mathrm{mM}$ PMSF). The lysates were sonicated and centrifuged at 12,000 RPM for $8 \mathrm{~min}$, and the clear supernatant was transferred to Eppendorf tubes. The protein content was quantified via a bicinchoninic acid assay, normalized and subjected to polyacrylamide gel electrophoresis. Protein expression was analyzed by western blot using specific antibodies for caveolin-1, clathrin, (EEA1), and $\beta$-tubulin as were previously described [16].

\section{Immunofluorescence Microscopy}

Immunofluorescence was performed as described previously [17] 


\begin{tabular}{|c|c|c|c|c|}
\hline Loading & Size (nm) & Charge (mV) & $\begin{array}{c}\text { Micelle Solubility } \\
\text { (mg/ml) }\end{array}$ & $\begin{array}{c}\mathbf{7 2} \text { h Release } \\
\text { rate (\%) }\end{array}$ \\
\hline $4.4 \%$ & 10.68 & -0.054 & 112.5 & 43.3 \\
\hline $14.5 \%$ & 12.40 & -0.064 & 43.4 & 19.8 \\
\hline $28.4 \%$ & 14.59 & -0.055 & 14.3 & 8.0 \\
\hline
\end{tabular}

Table 1: Characterization of SMA-Dox micelles.

The three different SMA-Dox micelles were synthesized and characterized with respect to their loading, size, charge, solubility and release rate at physiological $\mathrm{pH}$

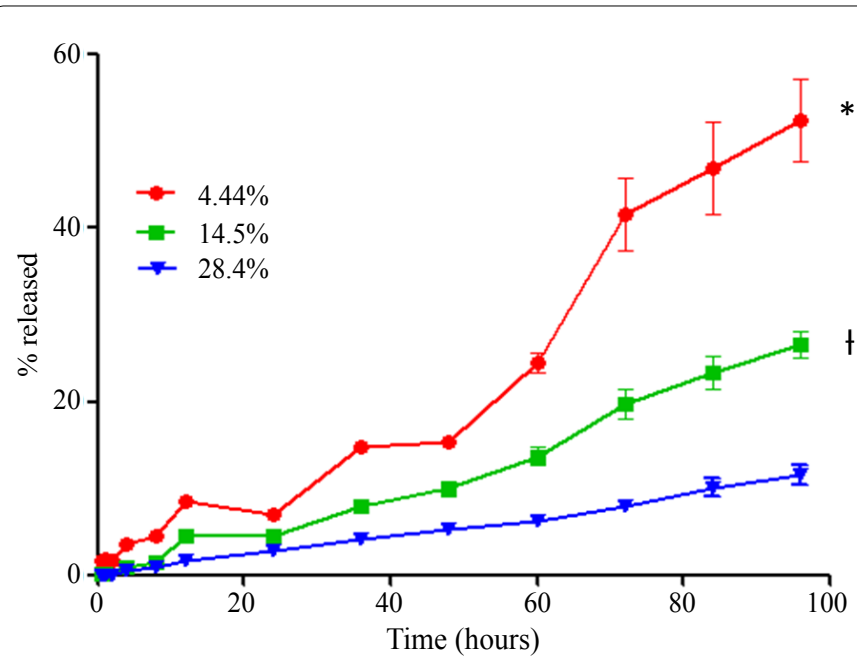

Figure 2: Release rate of doxorubicin from SMA-Dox was evaluated using a dialysis in PBS, pH 7.4, over a period of 96 hours. Data is expressed as mean \pm SEM $(n=3)$. ${ }^{*} P<0.005$ relative to $14.5 \%$ and $28.4 \%,{ }^{+} P<0.005$ relative to $28.4 \%$.

PC3 cells (20,000 cells/well) were seeded on glass slides and incubated for 36 hours before being pretreated with genistein $(200 \mu \mathrm{M})$ for one hour before being treated with SMA-Dox $(25 \mu \mathrm{M})$ or treated with SMA-Dox $(25 \mu \mathrm{M})$ for 6 hours. Cells were washed twice with ice-cold PBS, fixed in $4 \%$ paraformaldehyde for $30 \mathrm{~min}$ at room temperature, washed with PBS, and permeabilised in $0.2 \%$ Triton-X100 in PBS for 5 min, followed by incubation with $1 \%$ bovine serum albumin in PBS for 1 hour. The cells were then incubated with anti-caveolin-1 and anti-clathrin antibodies $(5 \mu \mathrm{g} / \mathrm{ml}$ in $\mathrm{PBS} /$ bovine serum albumin, as above) overnight at $4^{\circ} \mathrm{C}$, then washed four times with PBS, followed by incubation with fluorescein-conjugated goat anti-rabbit IgG $(10 \mu \mathrm{g} /$ $\mathrm{ml}$ in PBS/bovine serum albumin) for 1 hour at room temperature. The cells were washed four times with PBS, and the coverslips were mounted using Gel/Mount aqueous mounting medium (Fisher, Pittsburgh, PA). The images were taken using a Nikon H600L fluorescent microscope.

\section{Statistical analysis}

The data was analysed using Graphpad Prism with a multiple t test analysis. Significance was set at $\mathrm{p} \leq 0.005$.

\section{Results}

\section{Characteristics}

In the current study, we generated three doxorubicin micelles with a loading of $4.4,14.5$ and $28.4 \%$ as determined by spectrometry at $479 \mathrm{~nm}$. We also confirmed that the drug was not altered by the encapsulation by the comparison of spectra of the encapsulated versus free doxorubicin. The micelles were all highly soluble in water with the lowest loading showing the highest solubility (Table 1). Furthermore, the size ranged from 10.68 to $14.59 \mathrm{~nm}$ (Table 1) indicating that the micelles were of sufficient size to be used in vivo as the macromolecules will escape renal filtration to remain in the circulation for a prolonged time compare to the free doxorubicin and accumulate preferentially in tissues with large fenestration such as the tumor based on the EPR effect. The charge of the micelles was near neutral (Table 1) which will be conducive to preventing unwanted opsonisation within the circulation.

\section{Drug release rate}

As shown in Figure 2, the loading of the SMA-Dox micelles significantly altered the release profile of doxorubicin. The lowest loading of $4.4 \%$ doxorubicin showed the highest release rate, releasing more than $50 \%$ of the doxorubicin load following four days incubation. In contrast, the highest loading of $28.4 \%$ doxorubicin showed less than $15 \%$ release following four days incubation. The micelle with a loading of $14.5 \%$ had a release of $24 \%$ following four days incubation. It is clear that there is an inverse relationship between the loading and the release rate of the drug from the micelles.

\section{In vitro cytotoxicity}

The micellar formulation of doxorubicin results in a reduced potency and efficacy compared to the free drug (Figure 3). The $28.4 \%$ loading micelle showed the highest efficacy against all cell lines examined relative to the lower loading micelles. However, the pattern of cytotoxicity observed in the cell lines varies significantly. In MDAMB-231 cells, the different micelles show statistically significant differences only when comparing the $4.4 \%$ to the $28.4 \%$ and no significant difference is observed between the $14.5 \%$ and the $28.4 \%$. Similarly, in PC3 cells no statistical significance is observed between the $14.5 \%$ and the $28.4 \%$ micelles while the $4.4 \%$ loaded micelles are significantly different from both the $14.5 \%$ and $28.4 \%$ micelles. In DU145 and MCF7 cells the relative potency and efficacy of the different loading micelles are significantly divergent with the higher loaded micelles producing statistically significantly increased cytotoxicity relative to the lower loading micelles (Figure 3).

\section{Internalisation}

The internalization of SMA-Dox micelles of different loading were compared to free doxorubicin in four different cell lines and measured by FACS after 6 hours (Figure 4). In PC3 cells (Figure 4A) the uptake of the micelles is larger than in the DU145 cell line (Figure 4B). In MDAMB-231cells the uptake of micelles is higher than in MCF-7 cell lines. In all cases the internalization of free doxorubicin was higher compared to micellar SMA-Dox regardless of loading. This is to be expected as internalisation of micelles is a time and energy dependent process as it requires endocytosis while the delivery of doxorubicin to the cell is mediated by diffusion.

\section{Western blot}

To associate the main endocytosis pathways on the observed cytotoxicity patterns in the different cell lines, we compared the relative cellular expression of proteins involved in endocytosis (caveolin-1, clathrin, early endosome antigen 1 (EEA1), and $\beta$-tubulin), by western blot (Figure 5). The western blot showed that clathrin expression was slightly higher in the breast cancer cell lines MDA-MB-231 and MCF7 than the prostate cancer cell lines PC3 and DU145 but that did not explain the differences observed in cytotoxicity nor did EEA1 expression. However, the difference in caveolin-1 expression between the cell lines was substantial. MDA-MB-231 cells showed very high expression of caveolin-1, PC3 cells showed median expression, DU145 cells showed low expression and MCF-7 cells showed undetectable caveolin-1 expression at this exposure time. 

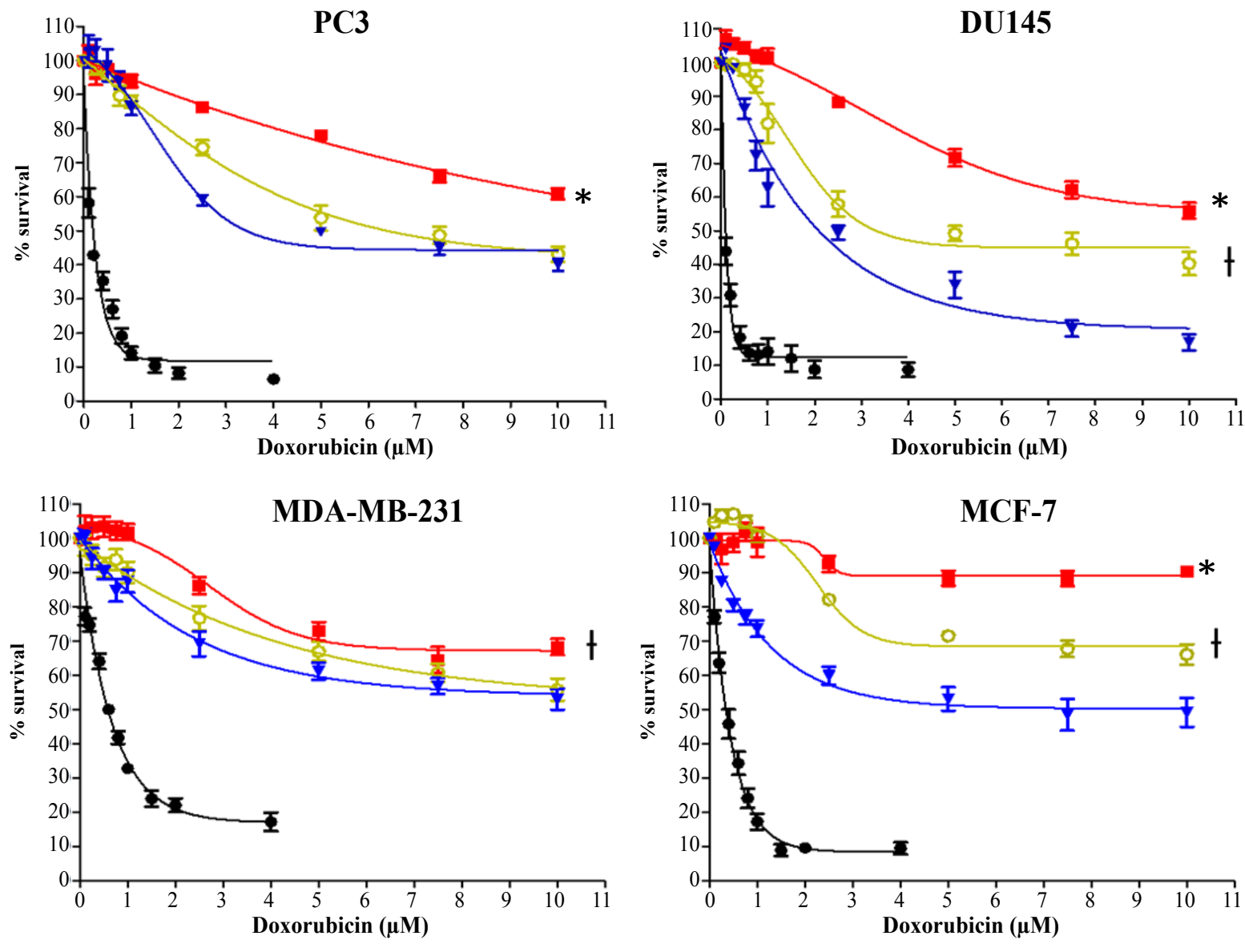

Free $\square .4 \%$

$14.5 \%$

- $28.4 \%$

Figure 3: Cytotoxicity of doxorubicin micelles against MCF7, MDA-MB-231, DU145 and PC3 cells following 72 hours of treatment. Cell number was determined using the sulforhodamine B assay. Data are expressed as mean \pm SEM $(n=3)$. ${ }^{*} P<0.005$ relative to $14.5 \%$ and $28.4 \%,{ }^{\dagger} P<0.005$ relative to $28.4 \%$. Non-linear regression and $\mathrm{IC}_{50}$ values determination was performed using GraphPad Prism. Cells were treated with various concentrations of the free drug and SMA-Dox micelles for $72 \mathrm{~h}$.

\section{Immunofluorescence microscopy}

In order to determine if caveolin-1 and doxorubicin micelles colocalized, immunocytochemistry was employed (Figure 6). Internalised doxorubicin micelles showed co-localization with caveolin-1 positive vesicles while pre-treatment for 1 hour with genistein, an inhibitor of the caveolin mediated endocytosis, significantly reduced the amount of intracellular doxorubicin and abolished the co-localisation of caveolin-1 positive vesicles and doxorubicin. This suggests that the differential cytotoxicity observed in these cell lines is dependent on the level of expression of protein implicated in the endocytic process and their capacity to endocytose macromolecules.

\section{Discussions}

The SMA micellar system, developed by Greish and Maeda [18], offers a variety of advantages due to its high versatility. The SMA micelle gives the potential to achieve a wide range of drug loading depending on the characteristics privileges, as this parameter will also precondition a slow or a fast release of the drug from the micelle [19-21]. This system differs from most micellar sytem engineered where the drug release rate shows pronounced biphasic characteristics [22-25]. We generated three
SMA micelles with doxorubicin loadings of $4.4,14.5$ or $28.4 \%$ (Table 1). Lower loading of the micelle resulted in increased solubility and a higher percentage of drug released (Table 1). The observed stability of micelle with higher drug load could be explained by the formation of a stronger hydrophobic core dictated by the interactions between the styrene moiety and doxorubicin [18]. Nonetheless, all micellar formulations showed stability characteristics suitable for the cancer treatment by engineering a macromolecule which size and release rate will ultimately decrease adverse effect to normal tissue and enabling its accumulation in the tumor, a process which usually requires more than 6 hours to be achieved [26].

Relative to free doxorubicin, the toxicity of micellar doxorubicin was reduced in all cell lines (Figure 3). Free doxorubicin enters the cell via diffusion or active transportation by the solute carrier family 22 member 16 (SLC22A16) [27] while micellar doxorubicin must be endocytosed, a time and energy dependent process that limits the uptake of drug into the cell. It must be noted, however, that in vitro assessment of cytotoxicity don't account for in vivo parameters such as biodistribution of the drug so, although the efficacy of SMA-Dox is reduced relative to free doxorubicin, this pattern is expected to be reversed in vivo as 

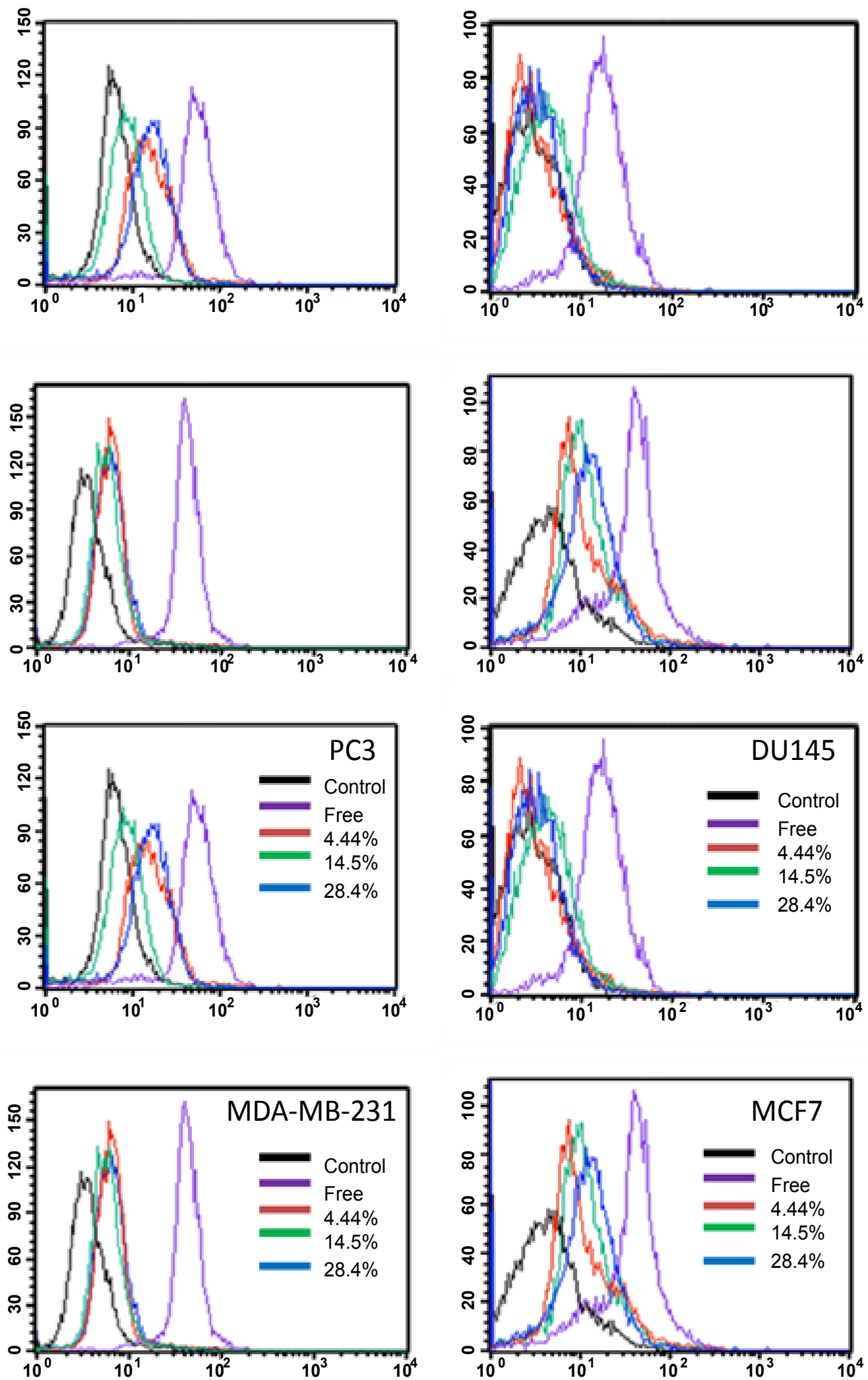

Figure 4: FACS analysis of the effect of loading on intercellular internalization of different loadings of SMA-Dox in four cancer cell lines. Uptake of SMA-Dox was higher in PC-3 cells than in DU145 cells. In MDA-MB-231 cells there appears to be a higher degree of micelle uptake then in MCF-7 cells. 


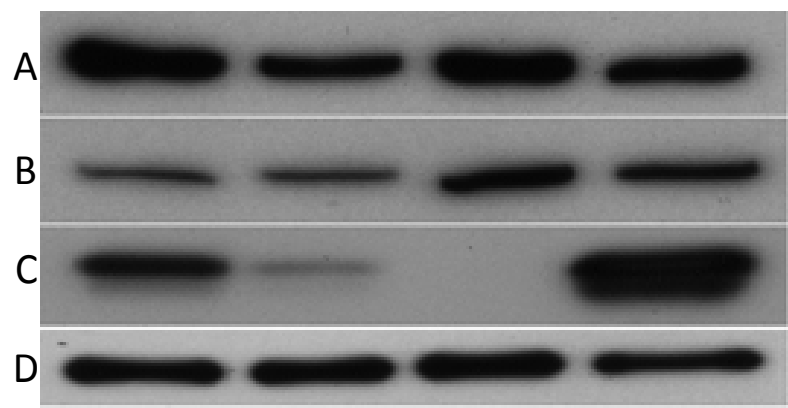

Figure 5: Western blot analysis of a) EEA1, b) clathrin, c) caveolin-1 and d) $\beta$-tubulin expression in PC3, DU145, MCF7 and MDA-MB-231 cancer cell lines.

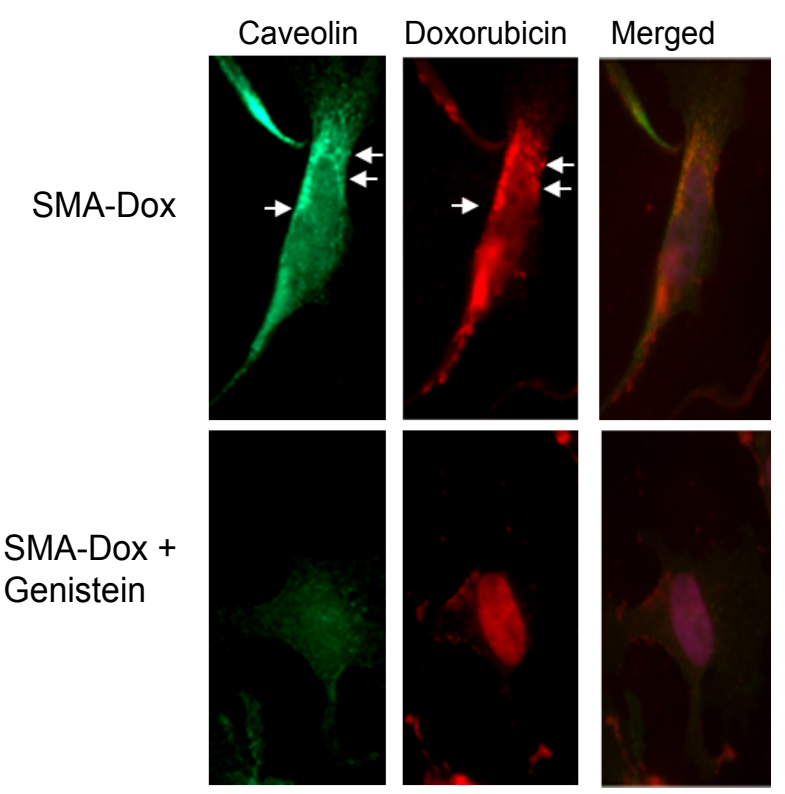

Figure 6: Co-localization of doxorubicin micelles, $28.4 \%$ loading (red), and caveolin-1 (FITC labeled) in PC3 cells with and without pre-treatment with $200 \mu \mathrm{M}$ of genistein. SMA-Dox micelles show co-localization with caveolin-1 vescicles that is abolished by co-treatment.

has been observed for other doxorubicin encapsulating nanomedicines, due to the EPR effect [28]. For example, Doxil, a commercially approved doxorubicin nanomedicine, has previously been shown to have a higher $\mathrm{IC}_{50}$ value than free doxorubicin in vitro $(2.5 \mathrm{ug} / \mathrm{ml}$ vs. $0.1 \mathrm{ug} / \mathrm{ml})$ [29], however subsequent in vivo evaluation has found that when mice are treated with a loading dose of $4.5 \mathrm{mg} / \mathrm{kg}$ and subsequent doses of 1 $\mathrm{mg} / \mathrm{kg}$ of doxorubicin equivalents every two days for five days, tumors of doxorubicin treated mice are 50\% larger than the tumors of Doxil treated mice [30].

We show for the first time that distinct patterns of cytotoxicity were observed relative to the drug content of the micelle. MDAMB-231 cells showed negligible dependence of cytotoxicity on the loading of the micelles at any concentration while PC3 cells showed a reduced differential effect of loading at higher concentrations. MCF-7 and DU145 cells showed a clear delineation between the cytotoxicity observed with different loadings at all concentrations with the higher micelle loading consistently showing more effective cytotoxicity towards the cell lines.
The distinct cytotoxic pattern suggests that the difference between the cell lines may be able to be explained by different uptake of the micelle. The western blot highlights the heterogeneity of caveolin-1 expression but not clathrin or EEA1 expression between the cell lines (Figure 5). This presents a possible mechanism for the cytotoxic patterns observed (Figure 1). For instance, MDA-MB-231 cells which display the highest expression of caveolin-1, show minimal difference between the potency and efficacy of the micelles relative to loading. This high caveolin-1 expression could indicate that the MDA-MB-231 cells are able to uptake the micelles rapidly and so, regardless of loading the maximal efficacy is achieved at each concentration. In DU145 and MCF7 cells, the expression of caveolin-1 is low and so the cells are not able to take up a large quantity of micelles, resulting in the cytotoxicity being dependent on the loading of the micelle as the cells are unable to take up a sufficient quantity of the micelles to reach maximum efficacy.

This conclusion is supported by the finding shown in Figure 6, where caveolin-1 positive vesicles overlaid the internalized SMADox. Inhibition of caveolin-1 by genistein abolished the formation of caveolin-1 positive vesicles, decreasing the quantity of internalised doxorubicin and dissociating the co-localisation of caveolin-1 and doxorubicin.

The maximal efficacy induced by the treatment appears to be dependent on the sensitivity of the cells to free doxorubicin and overall uptake of the micelles. The resistance of cells to doxorubicin is dependent on a wide variety of factors including, but not limited to, the relative expression of P-glycoprotein (an efflux protein), caspase I (an apoptosis mediator), heat shock proteins and CYP27A1 (a drug metabolising enzyme) which vary in expression from cell line to cell line [31,32]. For example MDA-MB-231 cells show a low efficacy of free doxorubicin with $18 \%$ of cells surviving at the highest free doxorubicin concentration $(4 \mu \mathrm{M})$. Therefore, although MDA-MB-231 cells show high caveolin-1 expression and so high uptake of SMADox, the relatively low sensitivity to the free drug was reflected in the low sensitivity to the micellar drug. Conversely, although MCF7 cells show a high degree of sensitivity to free doxorubicin, the efficacy of the SMA-Dox is low which may be due to the low expression of caveolin-1 resulting in insufficient quantities of SMA-Dox being taken up to elicit comparable cytotoxicity.

The association of micelle uptake with caveolin-1 expression gives important information for the selection of the types of tumours that will be suitable for treatment using macromolecules for drug delivery. For example, basal-like subtype breast tumors, represented in our study by MDA-MB-231 cells, show an increased expression of caveolin-1 than the luminal subtype [33] which is represented in our study by the MCF7 cell line. For this reason treatment of basal-like breast cancer subtype with SMA micelles is likely to be more effective than the treatment of luminal A type tumours.

The establishment of caveolin- 1 as the mechanism for uptake of the SMA micelles appears to be made more significant to clinical application via the observations of the role of caveolin-1 in the clinic. While caveolin-1 expression is often considered to play a tumor suppressive role in vitro and during early tumour development, the expression of caveolin-1 in later stages of tumour development is correlated with metastasis and chemoresistance [34]. Nanomedicines that are taken up via caveolin-1 will therefore be preferentially taken up in cells with high caveolin-1 expression, the same cells that are developing metastasis and allowing the tumour to grow despite chemotherapeutic treatments [34].

Further, the identification of caveolin- 1 as the endocytic mechanism 
Citation: Nehoff H, Parayath NN, Taurin S, Greish K (2014) The Influence of Drug Loading on Caveolin-1 Mediated Intracellular Internalization of Doxorubicin Nanomicelles in vitro. J Nanomed Nanotechnol 5: 197. doi:10.4172/2157-7439.1000197

for uptake of SMA micelles in the examined tumor cell lines contradicts reports suggesting that uptake mechanism is determined by size. For example, it has been suggested that uptake through clathrin mediated endocytosis is typical for particles $<200 \mathrm{~nm}[35]$ and $\sim 60 \mathrm{~nm} \mathrm{[36]} \mathrm{in}$ size, far in excess of the 10.68-14.5 $\mathrm{nm}$ size of the micelles assessed in this study. Furthermore, endocytosis has been shown in other studies to be dependent on factors as diverse as size, charge, shape, porosity and surface chemistry [37-41]. The degree of caveolin-1 expression varies between the different tumor cell lines and was shown to influence nanoconstructs' internalization and activity. This specification of the uptake mechanism of nanomedicines is frequently overlooked and may potentially contribute to nanomedicines being applied to tumour types to which their use is not suited. Careful understanding of cell specific interaction with nanomaterials is crucial for achieving a satisfactory biological outcome of nanoconstructs and can improve their potential for clinical application.

\section{Acknowledgements}

This work has been supported by OSMS Strategic Research Fund (108749.01.S.LM) and 2013 UORG (109420.01.R.LM)

\section{References}

1. Taurin S, Nehoff H, Greish K (2012) Anticancer nanomedicine and tumor vascular permeability; Where is the missing link? J Control Release 164: 265275

2. Hande KR (1998) Clinical applications of anticancer drugs targeted to topoisomerase II. Biochim Biophys Acta 1400: 173-184.

3. Cutts SM, Nudelman A, Rephaeli A, Phillips DR (2005) The power and potential of doxorubicin-DNA adducts. IUBMB Life 57: 73-81.

4. Müller I, Niethammer D, Bruchelt G (1998) Anthracycline-derived chemotherapeutics in apoptosis and free radical cytotoxicity (Review). Int J Mol Med 1: 491-494.

5. Greish K (2007) Enhanced permeability and retention of macromolecular drugs in solid tumors: a royal gate for targeted anticancer nanomedicines. J Drug Target 15: 457-464.

6. Shi Y, Moon M, Dawood S, McManus B, Liu PP (2011) Mechanisms and management of doxorubicin cardiotoxicity. Herz 36: 296-305.

7. O'Brien ME, Wigler N, Inbar M, Rosso R, Grischke E, et al. (2004) Reduced cardiotoxicity and comparable efficacy in a phase III trial of pegylated liposomal doxorubicin $\mathrm{HCl}$ (CAELYX/Doxil) versus conventional doxorubicin for first-line treatment of metastatic breast cancer. Ann Oncol 15: 440-449.

8. Batist G, Harris L, Azarnia N, Lee LW, Daza-Ramirez P (2006) Improved antitumor response rate with decreased cardiotoxicity of non-pegylated liposomal doxorubicin compared with conventional doxorubicin in first-line treatmen of metastatic breast cancer in patients who had received prior adjuvan doxorubicin: results of a retrospective analysis. Anticancer Drugs 17: 587-595.

9. Matsumura Y, Maeda H (1986) A new concept for macromolecular therapeutics in cancer chemotherapy: mechanism of tumoritropic accumulation of proteins and the antitumor agent smancs. Cancer Res 46: 6387-6392.

10. Hashizume H, Baluk P, Morikawa S, McLean JW, Thurston G, et al. (2000) Openings between defective endothelial cells explain tumor vessel leakiness. Am J Pathol 156: 1363-1380.

11. Maeda H, Bharate GY, Daruwalla J (2009) Polymeric drugs for efficient tumortargeted drug delivery based on EPR-effect. Eur J Pharm Biopharm 71: 409419

12. Leu AJ, Berk DA, Lymboussaki A, Alitalo K, Jain RK (2000) Absence of functional lymphatics within a murine sarcoma: a molecular and functional evaluation. Cancer Res 60: 4324-4327.

13. Greish K, Nagamitsu A, Fang J, Maeda H (2005) Copoly(styrene-maleic acid)pirarubicin micelles: high tumor-targeting efficiency with little toxicity. Bioconjug Chem 16: 230-236

14. Vichai V, Kirtikara K (2006) Sulforhodamine B colorimetric assay for cytotoxicity screening. Nat Protoc 1: 1112-1116.
15. Orlov SN, Taurin S, Tremblay J, Hamet $P$ (2001) Inhibition of $\mathrm{Na}^{+}, \mathrm{K}^{+}$pump affects nucleic acid synthesis and smooth muscle cell proliferation via elevation of the $\left[\mathrm{Na}^{+}\right] \mathrm{i} /\left[\mathrm{K}^{+}\right]$i ratio: possible implication in vascular remodelling. J Hypertens 19: $1559-1565$

16. Taurin S, Sandbo N, Yau DM, Sethakorn N, Dulin NO (2008) Phosphorylation of beta-catenin by PKA promotes ATP-induced proliferation of vascular smooth muscle cells. Am J Physiol Cell Physiol 294: C1169-1174.

17. Taurin S, Sandbo N, Qin Y, Browning D, Dulin NO (2006) Phosphorylation of beta-catenin by cyclic AMP-dependent protein kinase. J Biol Chem 281: 9971 9976.

18. Greish K, Sawa T, Fang J, Akaike T, Maeda H (2004) SMA-doxorubicin, a new polymeric micellar drug for effective targeting to solid tumours. $J$ Control Release 97: 219-230.

19. Nasongkla N, Shuai X, Ai H, Weinberg BD, Pink J, et al. (2004) cRGDfunctionalized polymer micelles for targeted doxorubicin delivery. Angew Chem Int Ed Engl 43: 6323-6327.

20. Sun H, Guo B, Li X, Cheng R, Meng F, et al. (2010) Shell-sheddable micelles based on dextran-SS-poly(epsilon-caprolactone) diblock copolymer for efficient intracellular release of doxorubicin. Biomacromolecules 11: 848-854.

21. Hrubý M, Konák C, Ulbrich K (2005) Polymeric micellar pH-sensitive drug delivery system for doxorubicin. J Control Release 103: 137-148.

22. Kataoka K, Matsumoto T, Yokoyama M, Okano T, Sakurai Y, et al. (2000) Doxorubicin-loaded poly(ethylene glycol)-poly(ß-benzyl-l-aspartate) copolymer micelles: their pharmaceutical characteristics and biological significance. $J$ Control Release 64: 143-153.

23. Zhang JX, Qiu LY, Jin Y, Zhu KJ (2006) Thermally responsive polymeric micelles self-assembled by amphiphilic polyphosphazene with poly $(\mathrm{N}$ isopropylacrylamide) and ethyl glycinate as side groups: Polymer synthesis, characterization, and in vitro drug release study. J Biomed Material Res A 76 : 773-780.

24. Tang R, Ji W, Panus D, Palumbo RN, Wang C (2011) Block copolymer micelles with acid-labile ortho ester side-chains: Synthesis, characterization, and enhanced drug delivery to human glioma cells. J Control Release 151: 18-27.

25. Yang X, Chen Y, Yuan R, Chen G, Blanco E et al. (2008) Folate-encoded and Fe3O4-loaded polymeric micelles for dual targeting of cancer cells. Polymer 49: 3477-3485

26. Noguchi Y, Wu J, Duncan R, Strohalm J, Ulbrich K, et al. (1998) Early phase tumor accumulation of macromolecules: a great difference in clearance rate between tumor and normal tissues. Jpn J Cancer Res 89: 307-314.

27. Thorn CF, Oshiro C, Marsh S, Hernandez-Boussard T, McLeod H, et al. (2011) Doxorubicin pathways: pharmacodynamics and adverse effects. Pharmacogenet Genomics 21: 440-446.

28. Zhao Q, Han B, Wang Z, Gao C, Peng C et al. (2007) Hollow chitosan-alginate multilayer microcapsules as drug delivery vehicle: doxorubicin loading and in vitro and in vivo studies. Nanomedicine: Nanotechnology, Biology and Medicine 3: $63-74$.

29. Ten Hagen TL, Van Der Veen AH, Nooijen PT, Van Tiel ST, Seynhaeve AL, e al. (2000) Low-dose tumor necrosis factor-alpha augments antitumor activity of stealth liposomal doxorubicin (DOXIL) in soft tissue sarcoma-bearing rats. Int J Cancer 87: 829-837.

30. Brouckaert P, Takahashi N, van Tiel ST, Hostens J, Eggermont AMM et al. (2004) Tumor necrosis factor-a augmented tumor response in B16BL6 melanoma-bearing mice treated with stealth liposomal doxorubicin (Doxil ${ }^{\circledR}$ ) correlates with altered Doxil ${ }^{\circledR}$ pharmacokinetics. Int J Cancer 109: 442-448.

31. Ciocca DR, Fuqua SA, Lock-Lim S, Toft DO, Welch WJ, et al. (1992) Response of human breast cancer cells to heat shock and chemotherapeutic drugs. Cancer Res 52: 3648-3654.

32. Györffy B, Serra V, Jürchott K, Abdul-Ghani R, Garber M, et al. (2005) Prediction of doxorubicin sensitivity in breast tumors based on gene expression profiles of drug-resistant cell lines correlates with patient survival. Oncogene 24: 7542 7551.

33. Elsheikh TM, Asa SL, Chan JK, DeLellis RA, Heffess CS, et al. (2008) Interobserver and intraobserver variation among experts in the diagnosis of thyroid follicular lesions with borderline nuclear features of papillary carcinoma. Am J Clin Pathol 130: 736-744

34. Carver LA, Schnitzer JE (2003) Caveolae: mining little caves for new cancer targets. Nat Rev Cancer 3: 571-581. 
Citation: Nehoff H, Parayath NN, Taurin S, Greish K (2014) The Influence of Drug Loading on Caveolin-1 Mediated Intracellular Internalization of Doxorubicin Nanomicelles in vitro. J Nanomed Nanotechnol 5: 197. doi:10.4172/2157-7439.1000197

Page 8 of 8

35. Rejman J, Oberle V, Zuhorn IS, Hoekstra D (2004) Size-dependent internalization of particles via the pathways of clathrin- and caveolae-mediated endocytosis. Biochem J 377: 159-169.

36. Petros RA, DeSimone JM (2010) Strategies in the design of nanoparticles for therapeutic applications. Nat Rev Drug Discov 9: 615-627.

37. Champion JA, Mitragotri S (2006) Role of target geometry in phagocytosis. Proc Natl Acad Sci U S A 103: 4930-4934.

38. Yu SS, Lau CM, Thomas SN, Jerome WG, Maron DJ, et al. (2012) Sizeand charge-dependent non-specific uptake of PEGylated nanoparticles by macrophages. Int J Nanomedicine 7: 799-813.
39. Tao Z, Toms BB, Goodisman J, Asefa T (2009) Mesoporosity and functional group dependent endocytosis and cytotoxicity of silica nanomaterials. Chem Res Toxicol 22: 1869-1880.

40. Chung TH, Wu SH, Yao M, Lu CW, Lin YS, et al. (2007) The effect of surface charge on the uptake and biological function of mesoporous silica nanoparticles in 3T3-L1 cells and human mesenchymal stem cells. Biomaterials 28: 29592966.

41. Slowing I, Trewyn BG, Lin VS (2006) Effect of surface functionalization of MCM41-type mesoporous silica nanoparticles on the endocytosis by human cancer cells. J Am Chem Soc 128: 14792-14793. 